\title{
How to Diagnose Sarcopenia in Korean Older Adults?
}

\author{
Hak Chul Jang; for the Sarcopenia Study Group of Korean Geriatrics Society \\ Department of Internal Medicine, Seoul National University Bundang Hospital, Seoul National University College of Medicine, Seongnam, \\ Korea
}

Corresponding Author:

Hak Chul Jang, MD

https://orcid.org/0000-0002-4188-6536

Department of Internal Medicine,

Seoul National University Bundang

Hospital, Seoul National University

College of Medicine, 82, Gumi-ro

173beon-gil, Bundang-gu, Seongnam

13620, Korea

Tel: +82-31-787- 7005

Fax: +82-31-787-4052

E-mail: janghak@snu.ac.kr

Received: June 1, 2018

Revised: June 11, 2018

Accepted: June 12, 2018
In 2017, Korea became an aged society, with the percentage of the population aged $\geq 65$ years accounting for $14 \%$ of the total Korean population. The increasing number of older adults and the current health status of Korean older adults had led to increased medical expenditure and social problems. Sarcopenia, defined as the progressive decrease in skeletal muscle mass and strength, develops as a consequence of aging. Sarcopenia is also associated with a risk of adverse health outcomes such as frailty, physical disability, poor quality of life, and death. Thus, sarcopenia is a serious clinical problem among older adults. The International Classification of Diseases, Tenth Revision, Clinical Modification code for sarcopenia, M62.84, became available on October 1, 2016, in the United States. The diagnosis and treatment of sarcopenia urgently requires the establishment of an operational definition for sarcopenia in Korean older adults. In this article, I suggest a screening strategy and diagnostic criteria for sarcopenia in this population. (Ann Geriatr Med Res 2018;22:73-79)

Key Words: Skeletal muscle, Diagnosis, Screen, Sarcopenia

\section{INTRODUCTION}

Increased life expectancy and declining fertility have brought about dramatic shifts in the age structure worldwide. ${ }^{1)}$ The number of older adults has increased substantially in recent years in most countries and regions. ${ }^{2)}$ This growth is projected to accelerate in the coming decades. Korea's population is also rapidly aging. A recent study published in The Lancet showed how life expectancy would change in 35 developed countries by 2030 using data from the World Health Organization. ${ }^{3)}$ According to this study, South Korea is likely to become the first country where life expectancy will exceed 90 years. In 2000, the percentage of population aged 65 years and over accounted for $7 \%$ of the total Korean population and this values increased to $14 \%$ by 2017 . $^{4)}$ Thus, Korea is one of the most rapid countries in terms of the speed of population aging.

According to the Survey of Korean Elderly Status in 2014 , about $90 \%$ of Korean older adults had more than 1 chronic disease diagnosed by physicians and $46 \%$ had more than 3 chronic diseases. ${ }^{5)}$ In general, Korean older adults have 2.6 chronic diseases. In addition, one-third of Korean older adults had depressive symptoms, as assessed by the short form of the Geriatric Depression Scale and an estimated 10\% of the total elderly population had dementia in 2016. ${ }^{6}$

The increasing number of older adults and the current health status of Korean older adults had led to increased medical expenditure under the National Health Insurance. In 2014, older people comprised $35.5 \%$ of medical expenses among National Health Insurance costs. ${ }^{7)}$

Humans have approximately 642 skeletal muscles and the skeletal muscle mass makes up $40 \%$ to $50 \%$ of the total body weight. Skeletal muscles have several crucial functions including posture, locomotion, and breathing. ${ }^{8)}$ Regulation of metabolism, heat production, and energy storage are also important functions of skeletal muscles.

The muscle mass progressively decreases after 20-30 years of age. Men have a greater muscle mass than women, but the loss of muscle mass is more rapid in men. ${ }^{9)}$ The loss of muscle mass is associated with a decrease in muscle strength and aerobic exercise capacity. The annual rate of muscle mass decline is about 1\%-2\% and accelerates to $2 \%-3 \%$ per year after 60 years of age; the rate further increases after the age of 75 years. ${ }^{10)}$ A 2-year study measuring the change in body composition using magnetic resonance imaging (MRI) in elderly African American women demonstrated significantly decreased muscle mass, especially in the lower extremities. ${ }^{11)}$ In contrast, fat mass, especially visceral and intermuscular fat, was increased. The decrease in skeletal muscle mass and the increase in ectopic fat is a common age-related remodeling of body composition.

The progressive decline in muscle mass and strength, termed sarcopenia, develops as a consequence of aging. ${ }^{12)}$ 
Sarcopenia may progress to frailty, loss of independence, physical disability, and increased mortality in older adults (Fig. 1). ${ }^{13-15)}$ Preservation of physical and cognitive function are important in the care of older people. A key strategy is to prevent the functional decline rather than attempting to recover functional loss. The US Centers for Disease Control and Prevention established an International Classification of Diseases, Tenth Revision, Clinical Modification code for sarcopenia, M62.84, which became available on October $1,2016 .{ }^{16)}$ Thus, establishment of an operational definition for sarcopenia and screening for sarcopenia before functional decline in older adults is urgently required. In this review, I discuss the diagnostic criteria for sarcopenia in Korean older adults.

\section{WHAT IS SARCOPENIA?}

The term sarcopenia, sarx for flesh and penia for loss, was first coined by Rosenberg ${ }^{17)}$ in 1988 when he described the age-associated decline of lean body mass. However, many studies indicated that the reduction of muscle strength was more involved compared to muscle loss in health outcomes related to sarcopenia ${ }^{12,18)}$ and that the relationship between strength and mass was not linear. ${ }^{19)}$ In 2010, the European Working Group on Sarcopenia in Older Persons (EWGSOP) defined sarcopenia as a syndrome characterized by a progressive and generalized loss of skeletal muscle mass with either muscle weakness or poor physical performance. ${ }^{12)}$ Several medical organizations subsequently proposed similar conceptional definitions of sarcopenia, such as age-related decrease of muscle mass with limited mobility. ${ }^{20,211}$ Sarcopenia is associated with a risk of adverse outcomes such as physical disability, poor quality of life, and death. These definitions for sarcopenia better demonstrated its associations with various health outcomes in older adults compared to definitions based only on muscle mass. ${ }^{12,22,23)}$

Several studies from Korea also demonstrated that sarcopenia was closely related to various adverse health outcomes, including functional disability, metabolic impairment, increased cardiovascular risk, and mortality in Korean older adults. ${ }^{14,15,24-27)}$

\section{HOW TO DIAGNOSE SARCOPENIA?}

Baumgartner et al. ${ }^{28)}$ first proposed the appendicular skeletal muscle mass (ASM) divided by height squared (ASM/height ${ }^{2}$ ) as a representative muscle index. He sug-

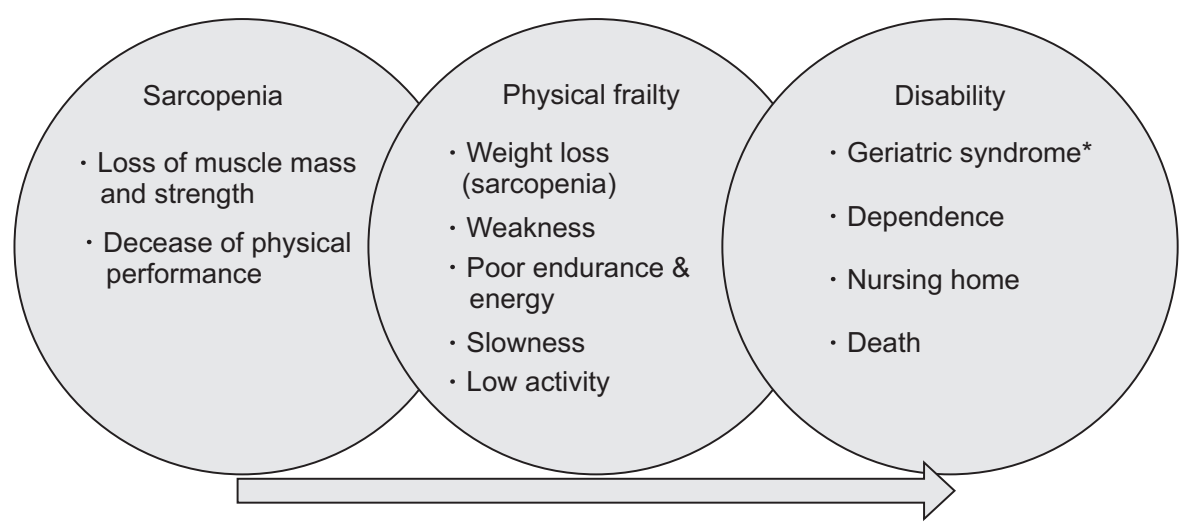

Fig. 1. Sarcopenia progression to frailty and disability. Sarcopenia is a major cause of frailty and one of the major components of frailty. It ultimately leads to disability, dependence, and death. *Geriatric syndrome: Incontinence, Falls, Pressure ulcer, Delirium, Functional decline

Table 1. Operational definitions for sarcopenia suggested by Baumgartner and medical organizations

\begin{tabular}{|c|c|c|c|c|}
\hline Study & Muscle mass index & $\begin{array}{l}\text { Grip strength } \\
\text { (kg) }\end{array}$ & $\begin{array}{l}\text { Gait speed } \\
\text { (m/sec) }\end{array}$ & Reference group \\
\hline Baumgartner et al. $(1998)^{28)}$ & $\begin{array}{l}\text { ASM } / \text { height }^{2}\left(\mathrm{~kg} / \mathrm{m}^{2}\right) \\
\text { Men, 7.26; women, } 5.5\end{array}$ & NA & NA & $\begin{array}{l}\text { Rosetta study (young reference } \\
\text { group) }\end{array}$ \\
\hline $\begin{array}{l}\text { European Working Group on } \\
\text { Sarcopenia in Older People }(2010)^{12), *}\end{array}$ & $\begin{array}{l}\text { ASM } / \text { height }^{2}\left(\mathrm{~kg} / \mathrm{m}^{2}\right) \\
\text { Men, 7.25; women, } 5.67\end{array}$ & $\begin{array}{l}\text { Men: }<30 \\
\text { Women: }<20\end{array}$ & $\begin{array}{l}\leq 0.8 \\
\leq 0.8\end{array}$ & $\begin{array}{l}\text { Health and body composition } \\
\text { (sex-specific, lowest } 20 \% \text { ) }\end{array}$ \\
\hline $\begin{array}{l}\text { International Working Group on } \\
\text { Sarcopenia }(2011)^{20)}\end{array}$ & $\begin{array}{l}\text { ASM } / \text { height }^{2}\left(\mathrm{~kg} / \mathrm{m}^{2}\right) \\
\text { Men, 7.23; women, } 5.67\end{array}$ & - & $\begin{array}{l}<1.0 \\
<1.0\end{array}$ & Health and body composition \\
\hline $\begin{array}{l}\text { Asian Working Group for Sarcopenia } \\
(2014)^{30)}\end{array}$ & $\begin{array}{l}\text { ASM } / \text { height }^{2}\left(\mathrm{~kg} / \mathrm{m}^{2}\right) \\
\text { Men, } 7.0 ; \text { women, } 5.4\end{array}$ & $\begin{array}{l}\text { Men: }<26 \\
\text { Women: }<18\end{array}$ & $\begin{array}{l}\leq 0.8 \\
\leq 0.8\end{array}$ & \\
\hline FNIH sarcopenia project $(2014)^{21)}$ & $\begin{array}{l}\text { ASM/BMI } \\
\text { Men, 0.789; women, } 0.512\end{array}$ & $\begin{array}{l}\text { Men: }<26 \\
\text { Women: }<16\end{array}$ & $\begin{array}{l}\leq 0.8 \\
\leq 0.8\end{array}$ & Pooled nine studies \\
\hline
\end{tabular}

ASM, appendicular skeletal muscle mass; NA, not available; BMI, body mass index; FNIH, Foundation for the National Institutes of Health.

*The cutoff point of the European Working Group on Sarcopenia in Older Persons definition for muscle index also includes that from Baumgartner et al. ${ }^{28)}$ 
gested the diagnostic criteria for sarcopenia as the ASM/ height $^{2}$ less than 2 standard deviations (SDs) below the mean of healthy young adults (Table 1). The EWGSOP recommended the presence of both low muscle mass and low muscle function (strength or performance) for the diagnosis of sarcopenia. ${ }^{12)}$ Measurements of muscle mass using dual-energy x-ray absorptiometry (DXA) or bioimpedance analysis (BIA), muscle strength by handgrip strength, and physical performance by gait speed or Short Physical Performance Battery were required for the diagnosis of sarcopenia.

As a cutoff point of low muscle mass, the EWGSOP suggested an ASM/height ${ }^{2}$ less than 2 SD below the genderspecific young reference groups or the lowest quintile of study populations such as the Health and body composition study. ${ }^{28,29)}$ The Asian Working Group for Sarcopenia (AWGS) also proposed diagnostic criteria for sarcopenia in Asian older people by adopting the recommendation of EWGSOP but considering ethnic differences in skeletal muscle mass and muscle strength. ${ }^{30)}$

Recently the Foundation for the National Institutes of Health (FNIH) Sarcopenia Project suggested new criteria for sarcopenia categorized by muscle mass, muscle strength, and physical performance. ${ }^{31)}$ They proposed a new muscle mass index of the ASM divided by body mass index (BMI).

\section{OPERATIONAL DEFINITION FOR SARCOPENIA IN KO- REAN OLDER ADULTS}

Kim et al. $^{32)}$ reported a prevalence of sarcopenia in Korean older people (defined by ASM/height ${ }^{2}<2$ SD of healthy young adults) as $9.3 \%$ in men and $0.2 \%$ in women using data from the 2008-2010 Korean National Health and Nutrition Examination Survey (KNHANES) (Fig. 2). Why was the prevalence of sarcopenia defined by the height-adjusted ASM very low in Korean older women?

The total muscle mass and ASM in Korean men increases rapidly until their 30s and then decreases continuously until 90 years of age, with a slight acceleration after 60 years of age. ${ }^{33)}$ This finding is similar to that for men in Western countries. ${ }^{9,10)}$ However, total muscle mass and ASM in women increases slowly until their 40s, remains constant until their 50s to 60s, and then begins to decrease (Fig. 3). The age trends for the height-adjusted and BMIadjusted ASM were similar to that of age-related change of ASM in Korean men (Fig. 4). However, in women, the age trend of muscle mass indices was substantially different among the height-adjusted, weight-adjusted and BMI-adjusted ASM. The peak of the height-adjusted ASM in women was around their 60s. This trend was different from that of Western countries. Thus, the low prevalence of sarcopenia by height-adjusted ASM in Korean older women is associated with a lower height-adjusted ASM of young reference in the Korean women.

Regarding the prevalence of sarcopenia using only skeletal muscle mass indices in Korean older people, the age trend in the prevalence of sarcopenia was commonly observed in all three indices in men (Fig. 2). However, the prevalence of sarcopenia was 2 fold higher for the BMIadjusted ASM using the FNIH criteria compared to that of height-adjusted ASM in the same age groups. The increasing trend in the prevalence of sarcopenia with aging was observed using BMI-adjusted ASM in Korean older women. These findings suggest that BMI-adjusted ASM might be a more appropriate skeletal muscle mass index in
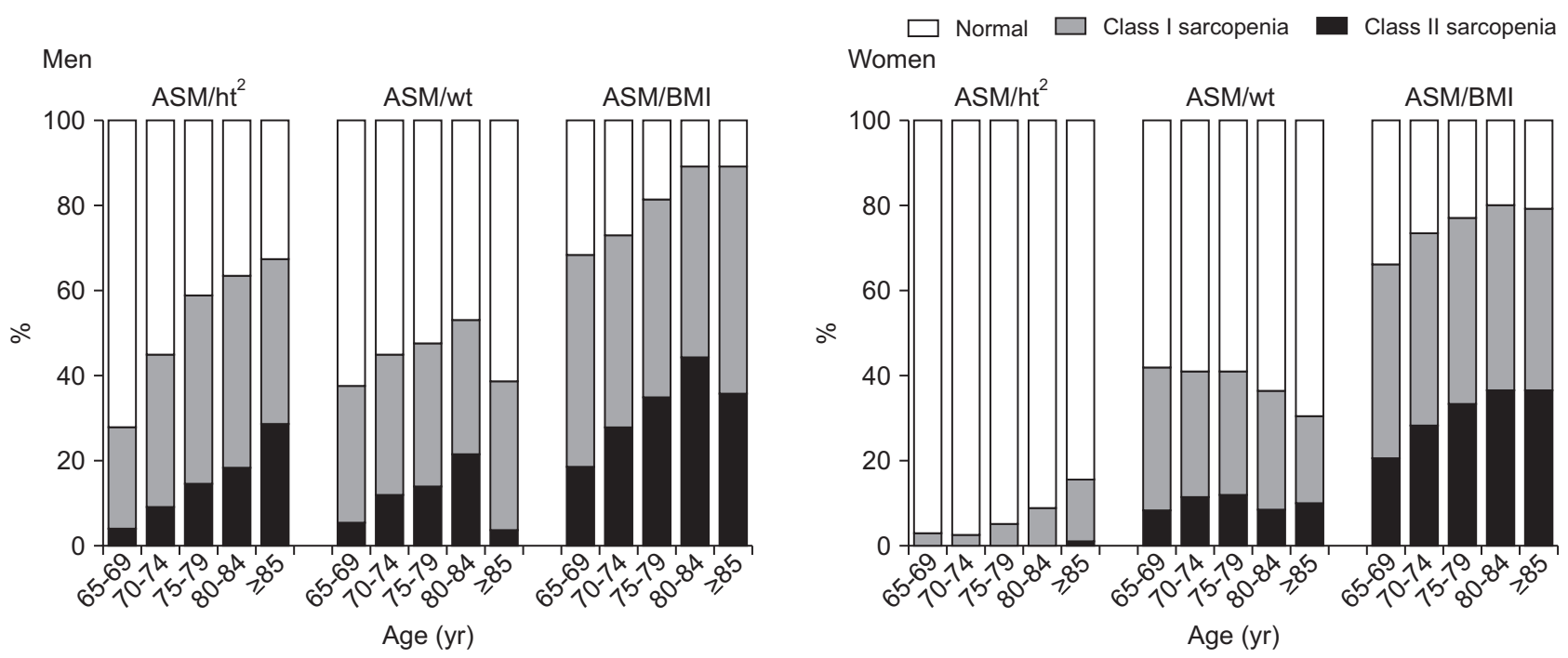

Fig. 2. Prevalence of sarcopenia as defined by various skeletal muscle indices in Korean older adults using data from the Korean National Health and Nutrition Examination Survey. Class I and class II sarcopenia were defined as muscle indices within -1.0 to -2.0 standard deviations (SDs) and below -2.0 SD of the sex-specific mean of young people (20 to 29 years). The cutoff points for sarcopenia (2 SD of the young reference) were $6.06 \mathrm{~kg} / \mathrm{m}^{2}, 27.43 \%$, and 0.784 in men and $4.07 \mathrm{~kg} / \mathrm{m}^{2}, 21.48 \%$, and 0.517 in women, respectively. ASM, appendicular skeletal muscle mass; BMI, body mass index; ht, height; wt, weight. Adapted from Kim et al. ${ }^{33)}$ 

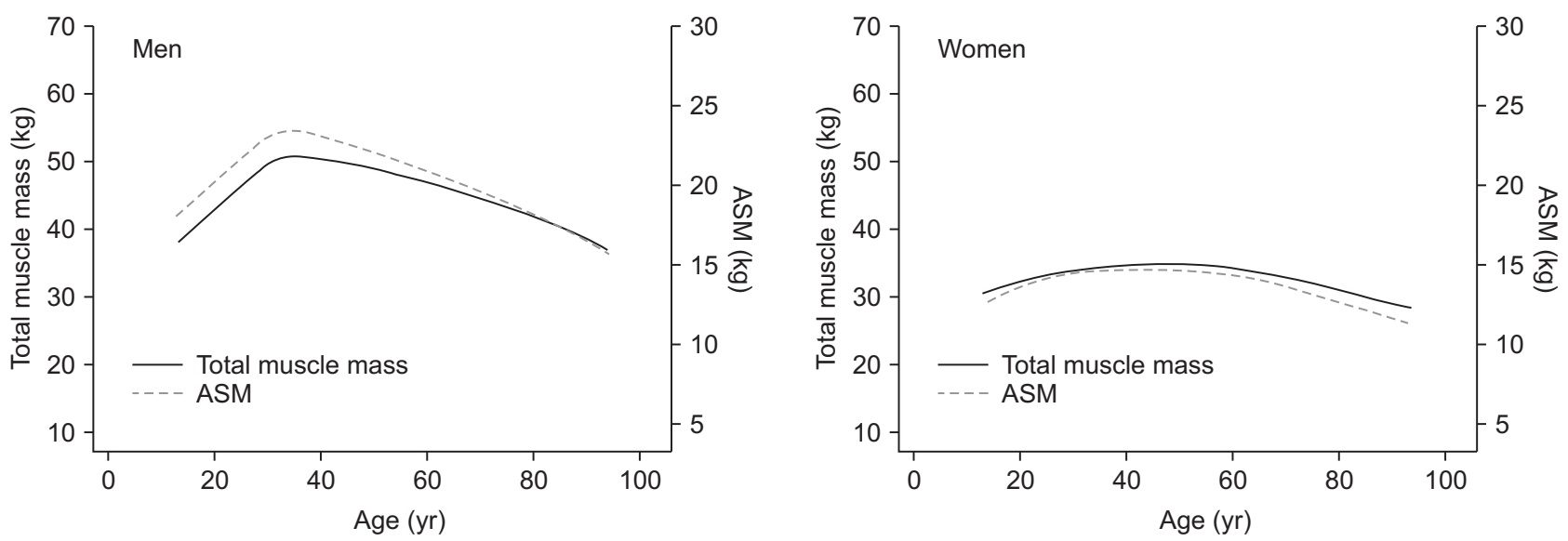

Fig. 3. Age trends of total muscle mass and appendicular skeletal muscle mass in Korean men and women. Trends of total muscle mass and appendicular skeletal muscle mass (ASM) according to age groups in Korean men and women using data from the 2008-2010 Korean National Health and Nutrition Examination Survey. Adapted from Kim et al. ${ }^{33)}$
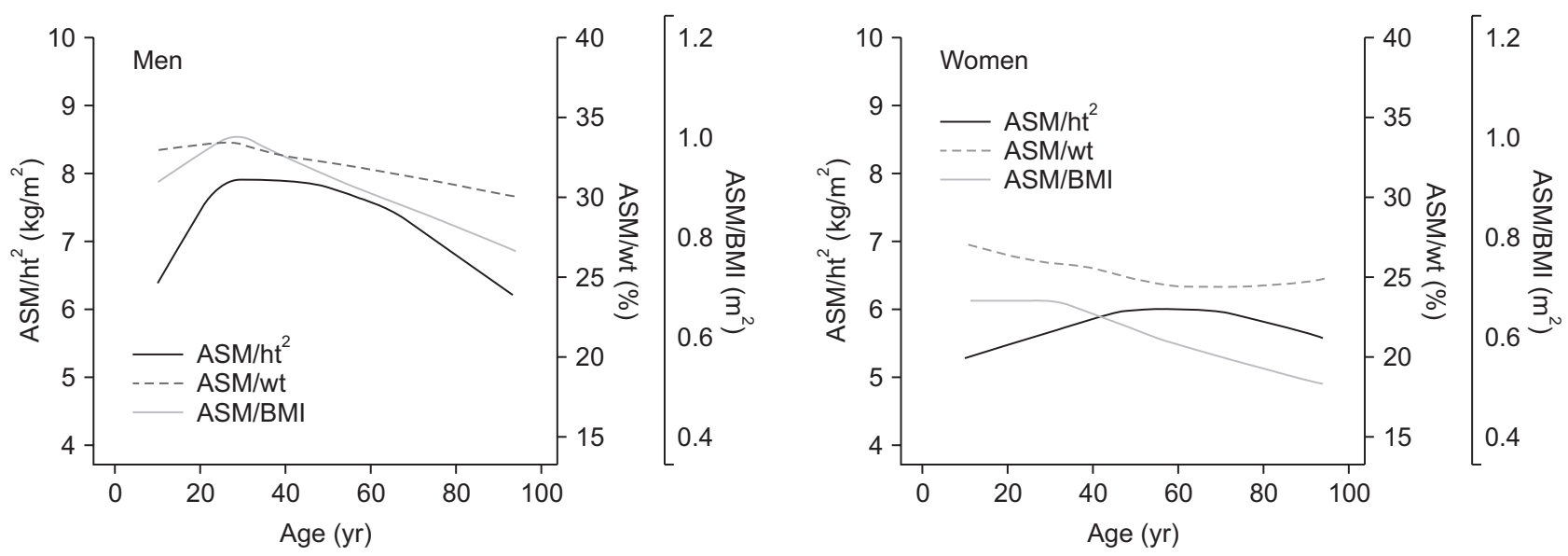

Fig. 4. Age trends of skeletal muscle mass indices in Korean men and women. The age trends of height-adjusted appendicular skeletal muscle mass (ASM) and body mass index (BMI)-adjusted ASM were similar to those of age-related change in ASM in Korean men. However, the age trend of muscle mass indices was quite different among the three indices in women. The peak of the height-adjusted ASM in women was around the sixties. Adapted from Kim et al. ${ }^{33)}$

Korean older adults, although further studies are needed to determine the cutoff points for sarcopenia in this population.

The Sarcopenia Study Group of Korean Geriatrics Society tried another approach for the diagnostic criteria of sarcopenia. They analyzed three cohort studies in Korea including the KNHANES, Korean Longitudinal Study of Health and Ageing and the Korean Genome and Epidemiology Study. ${ }^{32)}$ These studies used DXA to measure the ASM. There was a slight difference in mean age, but the mean ASM and ASM $/$ height $^{2}$ were similar in each gender among the 3 studies (Table 2). They suggested the lowest quintile of height-adjusted ASM of the KNHANES as a cutoff point for the diagnosis of sarcopenia in Korean older adults because the KNHANES was a nationwide and population-based study. The Sarcopenia Study Group of KGS recommends an operational definition of sarcopenia in Korean older adults as shown in Table 3.
The cutoff point for grip strength in Korean older adults was based on the 2015 Report of National Physical Fitness Survey from the Korea Institute of Sport Science. ${ }^{34)}$ Recently, Yoo et al. ${ }^{35)}$ reported cutoff values of grip strength in Korean older men and women of 28.6 and $16.4 \mathrm{~kg}$, respectively, using data from the KNHANES VI. Further studies are necessary to determine the cutoff points for Korean older adults. The cutoff point for gait speed in Korean older adults was adopted from the AWGS because there is currently no available representative study on gait speed in this population. Recently, Hong et al. ${ }^{36)}$ demonstrated that the slower gait speed $(<0.4 \mathrm{~m} / \mathrm{sec}$ for $2.5 \mathrm{~m})$ was associated with increased 3-year mortality using data from the Survey of Korean Elderly Status in 2008 and 2011. Jung et al. $^{37)}$ also showed that the first quartile of sex-specific gait speed (men, $0.663 \mathrm{~m} / \mathrm{sec}$; women, $0.545 \mathrm{~m} / \mathrm{sec}$ ) was associated with an increased risk of death or institutionalization in community-dwelling rural older people. These 
Table 2. Lowest quintile of the height-adjusted appendicular skeletal muscle mass in Korean older adults from 3 cohort studies ${ }^{32)}$

\begin{tabular}{|c|c|c|c|c|c|}
\hline Study & No & Age (yr) & ASM $(\mathrm{kg})$ & $\begin{array}{l}\text { ASM/height } \\
\left(\mathrm{kg} / \mathrm{m}^{2}\right)\end{array}$ & 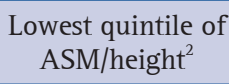 \\
\hline \multicolumn{6}{|c|}{ KNHANES (2008-2010) } \\
\hline Men & 1,361 & $72.2 \pm 5.4$ & $19.3 \pm 2.8$ & $7.1 \pm 0.8$ & 6.43 \\
\hline Women & 1,923 & $72.9 \pm 5.9$ & $13.4 \pm 1.9$ & $5.9 \pm 0.7$ & 5.34 \\
\hline \multicolumn{6}{|l|}{ KLoSHA } \\
\hline Men & 318 & $75.9 \pm 8.6$ & $18.6 \pm 3.2$ & $6.9 \pm 0.8$ & 6.19 \\
\hline Women & 315 & $76.0 \pm 8.8$ & $12.8 \pm 2.3$ & $5.6 \pm 0.9$ & 5.11 \\
\hline \multicolumn{6}{|l|}{ KoGES } \\
\hline Men & 435 & $71.2 \pm 3.6$ & $19.0 \pm 2.0$ & $7.1 \pm 0.7$ & 6.49 \\
\hline Women & 284 & $71.0 \pm 3.5$ & $13.2 \pm 1.6$ & $5.9 \pm 0.6$ & 5.39 \\
\hline
\end{tabular}

Values are presented as mean \pm standard deviation.

ASM, appendicular skeletal muscle mass; KNHANES, Korean National Health and Nutrition Examination Survey; KLoSHA, Korean Longitudinal Study on Health and Aging; KoGES, Korean Genome and Epidemiology Study.

Table 3. Cutoff points for the diagnosis of sarcopenia in Korean older adults

\begin{tabular}{|c|c|c|c|c|}
\hline Study & $\begin{array}{l}\text { ASM/height } \\
\left(\mathrm{kg} / \mathrm{m}^{2}\right)\end{array}$ & $\begin{array}{l}\text { Grip strength } \\
(\mathrm{kg})\end{array}$ & $\begin{array}{l}\text { Gait speed } \\
\text { (m/sec) }\end{array}$ & $\begin{array}{l}\text { Reference group } \\
\text { of muscle index }\end{array}$ \\
\hline $\begin{array}{l}\text { European Working Group on Sarcopenia } \\
\text { in Older People }(2010)^{12)}\end{array}$ & $\begin{array}{l}\text { Men: } 7.25 \\
\text { Women: } 5.67\end{array}$ & $\begin{array}{l}<30 \\
<20\end{array}$ & $\begin{array}{l}\leq 0.8 \\
\leq 0.8\end{array}$ & $\begin{array}{l}\text { Health and body composition } \\
\text { (sex-specific, lowest 20\%) }\end{array}$ \\
\hline $\begin{array}{l}\text { Asian Working Group for Sarcopenia } \\
(2014)^{30)}\end{array}$ & $\begin{array}{l}\text { Men: } 7.0 \\
\text { Women: } 5.4\end{array}$ & $\begin{array}{l}<26 \\
<18\end{array}$ & $\begin{array}{l}\leq 0.8 \\
\leq 0.8\end{array}$ & \\
\hline Sarcopenia Study Group of KGS (2015) & $\begin{array}{l}\text { Men: } 6.43 \\
\text { Women: } 5.34\end{array}$ & $\begin{array}{l}<26^{*} \\
<16^{*}\end{array}$ & $\begin{array}{l}\leq 0.8 \\
\leq 0.8\end{array}$ & $\begin{array}{l}\text { KNHANES (sex-specific, lowest } \\
\text { 20\%) }\end{array}$ \\
\hline
\end{tabular}

KNHANES, Korean National Health and Nutrition Examination Survey.

*Korea Institute of Sport Science, Report of national physical fitness survey $2015 .^{34)}$

studies clearly demonstrated that the gait speed is an important predictor for poor health outcomes in Korean older people. However, further studies are needed to determine the optimal cutoff point of gait speed in this population.

\section{SCREENING STRATEGY FOR SARCOPENIA IN KOREA}

The EWGSOP recommends routine screening for sarcopenia among community-dwelling older people over 65 years of age by measuring gait speed. ${ }^{12)}$ Meanwhile, the International Working Group on Sarcopenia (IWGS) suggests that sarcopenia should be evaluated in older patients with certain conditions including noted decline in function, strength, and health status; self-reported mobilityrelated difficulty; history of recurrent falls; recent unintentional weight loss (>5\%); posthospitalization; and other chronic conditions. ${ }^{20)}$ In addition, the IWGS recommends gait speed as a screening test and assessment of muscle mass by DXA in patients with a gait speed $<1.0 \mathrm{~m} / \mathrm{sec}$.

The AWGS recommends screening for sarcopenia among community-dwelling older adults as well as older adults with certain clinical conditions in all healthcare settings, ${ }^{30)}$ similar to IWGS recommendations. The AWGS also suggests grip strength and gait speed as screening tools, and that muscle mass in older adults with low grip strength and/or low gait speed should be assessed by DXA or BIA.

In Korea, there are no consensus or guidelines for the screening of sarcopenia in older adults. However, the recommendations of the AWGS are appropriate in this population. DXA is a better tool for the measurement of skeletal muscle mass because the assessment of skeletal muscle mass using BIA requires further research for application in Korean older adults. ${ }^{38)}$

\section{CONCLUSION}

With rapid population aging, there is a remarkable increase in the number of older adults in Korea. Sarcopenia, a progressive decline in muscle mass and strength, develops as a consequence of aging and may progress to frailty, loss of independence, physical disability, and increased mortality in older adults. Thus, sarcopenia has become a serious clinical problem in older adults. For the diagnosis and treatment of sarcopenia and the prevention of frailty or disability in older people, it is necessary to establish diagnostic criteria for sarcopenia in Korean older adults. In this review, I suggested a screening strategy and diagnostic criteria for sarcopenia for Korean older adults.

Conflicts of Interest Disclosures: The researcher claims no conflicts of interest. 


\section{ACKNOWLEDGMENTS}

This work was supported by the Ministry of Health and Welfare, Republic of Korea (grant number: HI15 C3207). I thank all members of the Sarcopenia Study Group of Korean Geriatrics Society for their comments and contributions.

\section{REFERENCES}

1. Population Reference Bureau. 2014 World population data sheet [Internet]. Washington, DC: Population Reference Bureau; c2018 [cited 2015 Jul 25]. Available from: http://www.prb.org/ pdf14/2014-world-population-data-sheet_eng.pdf.

2. United Nations, Department of Economic and Social Affairs, Population Division. World population ageing 2015 (ST/ESA/SER. A/390). New York: United Nation; 2015.

3. Kontis V, Bennett JE, Mathers CD, Li G, Foreman K, Ezzati M. Future life expectancy in 35 industrialised countries: projections with a Bayesian model ensemble. Lancet 2017;389:1323-35.

4. Kim SM, Jang HT. Korea officially becomes aged society. The ChosunIlbo [Internet]. 2017 Sep 4 [cited 2018 Apr 21]. Available from: http://english.chosun.com/site/data/html_ dir/2017/09/04/2017090401307.html.

5. The Korea Institute for Health and Social Affairs. Survey of Korean elderly status, 2014. Sejong (Korea): Korea Ministry of Health and Welfare; 2014.

6. Kim YJ, Han JW, So YS, Seo JY, Kim KY, Kim KW. Prevalence and trends of dementia in Korea: a systematic review and metaanalysis. J Korean Med Sci 2014;29:903-12.

7. Sun U. Policy issues in elderly health and long-term care policy. Health Welf Forum 2016;239:34-48.

8. Frontera WR, Ochala J. Skeletal muscle: a brief review of structure and function. Calcif Tissue Int 2015;96:183-95.

9. Short KR, Vittone JL, Bigelow ML, Proctor DN, Nair KS. Age and aerobic exercise training effects on whole body and muscle protein metabolism. Am J Physiol Endocrinol Metab 2004;286:E92101.

10. Hughes VA, Frontera WR, Roubenoff R, Evans WJ, Singh MA. Longitudinal changes in body composition in older men and women: role of body weight change and physical activity. Am J Clin Nutr 2002;76:473-81.

11. Song MY, Ruts E, Kim J, Janumala I, Heymsfield S, Gallagher D. Sarcopenia and increased adipose tissue infiltration of muscle in elderly African American women. Am J Clin Nutr 2004;79:87480.

12. Cruz-Jentoft AJ, Baeyens JP, Bauer JM, Boirie Y, Cederholm T, Landi F, et al. Sarcopenia: European consensus on definition and diagnosis: report of the European Working Group on Sarcopenia in Older People. Age Ageing 2010;39:412-23.

13. Kelley GA, Kelley KS. Is sarcopenia associated with an increased risk of all-cause mortality and functional disability? Exp Gerontol 2017;96:100-3.

14. Kim JH, Choi SH, Lim S, Yoon JW, Kang SM, Kim KW, et al. Sarcopenia and obesity: gender-different relationship with functional limitation in older persons. J Korean Med Sci 2013;28:1041-7.
15. Kim JH, Lim S, Choi SH, Kim KM, Yoon JW, Kim KW, et al. Sarcopenia: an independent predictor of mortality in communitydwelling older Korean men. J Gerontol A Biol Sci Med Sci 2014; 69:1244-52.

16. Anker SD, Morley JE, von Haehling S. Welcome to the ICD-10 code for sarcopenia. J Cachexia Sarcopenia Muscle 2016;7:512-4.

17. Rosenberg IH. Sarcopenia: origins and clinical relevance. J Nutr 1997;127(5 Suppl):990S-991S.

18. Newman AB, Kupelian V, Visser M, Simonsick EM, Goodpaster BH, Kritchevsky SB, et al. Strength, but not muscle mass, is associated with mortality in the health, aging and body composition study cohort. J Gerontol A Biol Sci Med Sci 2006;61:72-7.

19. Goodpaster BH, Park SW, Harris TB, Kritchevsky SB, Nevitt M, Schwartz AV, et al. The loss of skeletal muscle strength, mass, and quality in older adults: the health, aging and body composition study. J Gerontol A Biol Sci Med Sci 2006;61:1059-64.

20. Fielding RA, Vellas B, Evans WJ, Bhasin S, Morley JE, Newman $A B$, et al. Sarcopenia: an undiagnosed condition in older adults. Current consensus definition: prevalence, etiology, and consequences. International Working Group on Sarcopenia. J Am Med Dir Assoc 2011;12:249-56.

21. Morley JE, Abbatecola AM, Argiles JM, Baracos V, Bauer J, Bhasin S, et al. Sarcopenia with limited mobility: an international consensus. J Am Med Dir Assoc 2011;12:403-9.

22. Landi F, Liperoti R, Russo A, Giovannini S, Tosato M, Capoluongo E, et al. Sarcopenia as a risk factor for falls in elderly individuals: results from the ilSIRENTE study. Clin Nutr 2012;31:652-8.

23. Woo J, Leung J, Sham A, Kwok T. Defining sarcopenia in terms of risk of physical limitations: a 5-year follow-up study of 3,153 chinese men and women. J Am Geriatr Soc 2009;57:2224-31.

24. Kim KE, Jang SN, Lim S, Park YJ, Paik NJ, Kim KW, et al. Relationship between muscle mass and physical performance: is it the same in older adults with weak muscle strength? Age Ageing 2012;41:799-803.

25. Lim S, Kim JH, Yoon JW, Kang SM, Choi SH, Park YJ, et al. Sarcopenic obesity: prevalence and association with metabolic syndrome in the Korean Longitudinal Study on Health and Aging (KLoSHA). Diabetes Care 2010;33:1652-4.

26. Kim KM, Lim S, Choi SH, Kim JH, Shin CS, Park KS, et al. Cardiometabolic implication of sarcopenia: The Korea National Health and Nutrition Examination Study (KNHANES) 2008-2010. IJC Metab Endoc 2014; 4:63-9.

27. Jang IY, Jung HW, Lee CK, Yu SS, Lee YS, Lee E. Comparisons of predictive values of sarcopenia with different muscle mass indices in Korean rural older adults: a longitudinal analysis of the Aging Study of PyeongChang Rural Area. Clin Interv Aging 2018;13:919.

28. Baumgartner RN, Koehler KM, Gallagher D, Romero L, Heymsfield SB, Ross RR, et al. Epidemiology of sarcopenia among the elderly in New Mexico. Am J Epidemiol 1998;147:755-63.

29. Newman AB, Kupelian V, Visser M, Simonsick E, Goodpaster B, Nevitt M, et al. Sarcopenia: alternative definitions and associations with lower extremity function. J Am Geriatr Soc 2003;51:1602-9.

30. Chen LK, Liu LK, Woo J, Assantachai P, Auyeung TW, Bahyah KS, et al. Sarcopenia in Asia: consensus report of the Asian Working Group for Sarcopenia. J Am Med Dir Assoc 2014;15:95-101. 
31. Studenski SA, Peters KW, Alley DE, Cawthon PM, McLean RR, Harris TB, et al. The FNIH sarcopenia project: rationale, study description, conference recommendations, and final estimates. J Gerontol A Biol Sci Med Sci 2014;69:547-58.

32. Kim KM, Lim S, Choi KM, Kim JH, Yu SH, Kim TN, et al. Sarcopenia in Korea: prevalence and clinical aspects. J Korean Geriatr Soc 2015;19:1-8.

33. Kim KM, Jang HC, Lim S. Differences among skeletal muscle mass indices derived from height-, weight-, and body mass index-adjusted models in assessing sarcopenia. Korean J Intern Med 2016; 31:643-50.

34. Korea Institute of Sport Science. Report of national physical fitness survey 2015. Seoul: Korea Institute of Sport Science; 2016.

35. Yoo J, Choi H, Ha YC. Mean hand grip strength and cut-off value for sarcopenia in Korean adults using KNHANES VI. J Korean Med Sci 2017;32:868-72.

36. Hong S, Won CW, Kim BS, Choi H, Kim S, Choi SE, et al. The cutoff point of gait speed as predictor of 3 year mortality in Korean community-dwelling elderly. Korean J Fam Pract 2016;6:166-71

37. Jung HW, Jang IY, Lee CJ, Yu SS, Hwang JK Jeon C, et al. Usual gait speed is associated with frailty status, institutionalization, and mortality in community-dwelling rural older adults: a longitudinal analysis of the Aging Study of Pyeongchang Rural Area. Clin Interv Aging 2018;13:1079-89.

38. Kim JH, Choi SH, Lim S, Kim KW, Lim JY, Cho NH, et al. Assessment of appendicular skeletal muscle mass by bioimpedance in older community-dwelling Korean adults. Arch Gerontol Geriatr 2014;58:303-7. 